\title{
BMJ Open Effect of a combined education and eHealth programme on the control of oral anticoagulation patients (PORTALS study): a parallel cohort design in Dutch primary care
}

\author{
Esther P W A Talboom-Kamp, ${ }^{1,2}$ Noortje A Verdijk, ${ }^{1,2}$ Marise J Kasteleyn, ${ }^{1}$ \\ Lara M Harmans, ${ }^{2}$ Irvin J S H Talboom, ${ }^{3}$ Mattijs E Numans, ${ }^{1}$ Niels H Chavannes ${ }^{1}$
}

To cite: Talboom-Kamp EPWA, Verdijk NA, Kasteleyn MJ, et al. Effect of a combined education and eHealth programme on the control of oral anticoagulation patients (PORTALS study): a parallel cohort design in Dutch primary care. BMJ Open 2017;7:e017909. doi:10.1136/ bmjopen-2017-017909

- Prepublication history and additional material for this paper are available online. To view, please visit the journal (http:// dx.doi.org/10.1136/bmjopen2017-017909).

Received 29 May 2017

Revised 24 August 2017

Accepted 31 August 2017

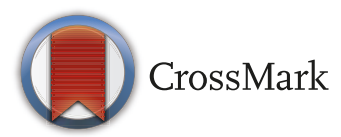

${ }^{1}$ Public Health and Primary Care Department, Leiden University Medical Centre, Leiden, The Netherlands

${ }^{2}$ Department of Thrombosis Service Centre, Saltro Diagnostic Centre, Utrecht, The Netherlands ${ }^{3}$ Department of Information Management, Caregroup DOH, Eindhoven, The Netherlands

Correspondence to

Esther P W A Talboom-Kamp; e.talboom@saltro.nl

\section{ABSTRACT}

Objectives To analyse the effect on therapeutic control and self-management skills of the implementation of selfmanagement programmes, including eHealth by e-learning versus group training.

Setting Primary Care Thrombosis Service Center. Participants of the 247 oral anticoagulation therapy (OAT) patients, 63 started self-management by e-learning, 74 self-management by group training and 110 received usual care.

Intervention and methods Parallel cohort design with two randomised self-management groups (e-learning and group training) and a group receiving usual care. The effect of implementation of self-management on time in therapeutic range (TTR) was analysed with multilevel linear regression modelling. Usage of a supporting eHealth platform and the impact on self-efficacy (Generalised SelfEfficacy Scale (GSES)) and education level were analysed with linear regression analysis. After intervention, TTR was measured in three time periods of 6 months.

Main outcome measures (1) TTR, severe complications,(2) usage of an eHealth platform,(3) GSES, education level.

Results Analysis showed no significant differences in TTR between the three time periods $(p=0.520)$, the three groups $(p=0.460)$ or the groups over time $(p=0.263)$. Comparison of e-learning and group training showed no significant differences in TTR between the time periods $(p=0.614)$, the groups $(p=0.460)$ or the groups over time $(p=0.263)$. No association was found between GSES and TTR $(p=0.717)$ or education level and TTR $(p=0.107)$. No significant difference was found between the selfmanagement groups in usage of the platform $(0-6$ months $p=0.571 ; 6-12$ months $p=0.866 ; 12-18$ months $p=0.260)$. The percentage of complications was low in all groups $(3.2 \% ; 1.4 \% ; 0 \%)$.

Conclusions No differences were found between OAT patients trained by e-learning or by a group course regarding therapeutic control (TTR) and usage of a supporting eHealth platform. The TTR was similar in selfmanagement and regular care patients. With adequate e-learning or group training, self-management seems safe and reliable for a selected proportion of motivated vitamin $\mathrm{K}$ antagonist patients.

\section{Strengths and limitations of this study}

- This study investigates the effect of different education and eHealth programmes in a situation as close to 'real life' as possible.

- The pragmatic study design will increase the applicability of the findings.

- The combination of clinical and usage data collection will give a deeper comprehension of the results.

- A potential limitation is that patients were free to volunteer, which might have caused bias in our study groups.

Trial registration number NTR3947.

\section{INTRODUCTION}

Venous thromboembolism (VTE) and atrial fibrillation (AF) are common causes of mortality and morbidity, with rising prevalence and medical costs. ${ }^{1-3}$ Oral anticoagulation therapy (OAT) reduces thromboembolic events in AF, prosthetic heart valves, acute myocardial infarction and other conditions, and is an effective treatment for VTE. ${ }^{4-6}$ The major risks of OAT are bleeding complications, with a rate of major bleeding among long-term users of vitamin $\mathrm{K}$ antagonists (VKAs) of $1.5 \%-5.2 \%$ per year. $^{7-9}$ There is a narrow therapeutic range for VKA, expressed as the international normalised ratio (INR) with an optimal intensity, related to a low rate of events, between 2.5 and 4.9. ${ }^{10} 11$ This is relevant, as patients have considerable difficulty in maintaining adequate adherence to VKA regimens, with a significant effect on anticoagulation control. ${ }^{12}$ Structured monitoring and coaching of patients using VKA is essential. This may be carried out by specialised centres in primary care or in hospitals. ${ }^{13}$ 
Alternatively, patients might choose to self-manage their VKA monitoring. In the case of VKA, self-management includes monitoring INR values by patients (self-monitoring) and, as a possible next step, self-adjustment of the medication dosage (self-dosage). Nowadays, patients are usually supported by improved eHealth supported self-management programme ${ }^{14}$ with more freedom, improved quality of life and self-efficacy and less burden of specialised centres. ${ }^{15} 16$ Research shows a reduction of thromboembolic events and in all-cause mortality for patients with self-management ${ }^{17}$ due to the fact that patients have greater responsibility, increased awareness, commitment and interest in their condition. ${ }^{18}$

Adequate self-management is important for all patients with OAT to improve adherence to medication, irrespective of the type of anticoagulation medicine they use. ${ }^{19-21}$ The basic principle of self-management is behavioural change, which is necessary to improve the quality of life of patients and the primary outcomes of their health and disease. ${ }^{22}$ Research on chronic diseases such as diabetes ${ }^{23}$ chronic obstructive pulmonary disease ${ }^{24}$ and heart failure ${ }^{25}$ has shown that aspects such as self-efficacy (belief in one's capabilities to organise and execute the course of action required to produce given attainments), educational level, socioeconomic status, age and sex are influencing factors in successful self-management and predictors in eHealth usage. ${ }^{26}$

As education is the basic approach in the development of self-management skills, the strategy used to implement educational support is expected to affect the individual level of self-management and, thereby, clinical outcomes. To test this hypothesis, we designed the PORTALS study. The aim of this study was to analyse the effect on anticoagulation control of an intervention consisting of an education programme in combination with the use of an online self-management portal. The general definition of self-management is the individual's ability to manage the symptoms, treatment, physical and psychosocial consequences and lifestyle changes inherent in living with a chronic condition ${ }^{27}$; in line with this definition, both self-monitoring and self-dosage of medication are considered important self-management skills in the PORTALS study (PORtal implementation within anTicoagulation care; AmpLification of Selfmanagement).

\section{METHODS}

\section{Study design}

For the PORTALS study, we designed a quality improvement intervention and compared strategies in an implementation study. ${ }^{28}$ Two methods were developed to train long-term VKA patients of the Saltro Thrombosis Service (outpatient anticoagulation clinic and laboratory) in self-management routine care. Using this design, we aimed to examine the influence of the training strategy on clinical outcomes and usage of the supporting eHealth platform. Full methodological details are reported elsewhere ${ }^{29}$; Table 1 presents an overview of the study design.

A parallel cohort design was used to investigate determinants of optimal implementation of self-management by comparing two different training methods. After inclusion, participants were randomly divided into subgroups: one group was trained and educated by e-learning (group 1) and the other group received face-to-face group training (group 2). Patients unable or unwilling to dose their medication were free to continue with only self-monitoring. Patients who did not wish to start with self-management were invited to participate in the non-self-management group, that is, a parallel cohort group receiving usual care (group 3). Group three provided valuable information about the patients who were unable/unwilling to use an online supported self-management programme.

Based on our parallel cohort design, comparison between e-learning and group training for self-management (group 1 and 2) and non-self-management patients (group 3) is applicable, considering the specific conditions in the choice of the statistics.

\section{Participants}

The present study focused on patients of the Saltro Thrombosis Service who voluntarily chose to start with self-management. The inclusion criteria for patients to start with self-management were a long-term indication for anticoagulants, internet access and stable INR values

\begin{tabular}{llll}
\hline Table 1 & Overview of the study design: details of groups 1,2 and 3 & \\
\cline { 2 - 4 } & \multicolumn{4}{l}{ Saltro Thrombosis Service Centre } & & Usual care \\
\cline { 2 - 4 } Self-management & Group 2 & Group 3 \\
\hline \multirow{4}{*}{ Patients } & Group 1 & $\# 72$ & Basic short training \\
& $\# 72$ & Group course & \\
& E-learning & Disease-specific knowledge & \\
& Disease-specific knowledge & Self-testing skills & \\
& Self-testing skills & Use of the web portal \\
& Use of the web portal & (voluntary) & \\
& (voluntary) & Self-adjustment of medication & \\
& Self-adjustment of medication & Self-management & \\
\hline
\end{tabular}


(at least three INR values in succession must be within therapeutic range). Patients who met the criteria for self-management were approached for participation in the study. Because self-management (including eHealth) is already an option for patients of the Saltro Thrombosis Service, the group training was also open to patients who were not willing to participate in the study. The e-learning was reserved for participants of the present study, as this was a new implementation method. All patients provided written informed consent before participation in the study.

\section{Patient involvement}

Patients were neither involved in the design nor in defining research questions and outcome measures of the study; however, they were actively involved in the development of the self-management platform Portavita. To maximise the involvement of patients, we did not randomise the intervention groups (self-management and usual care); we chose a recruitment design in which patients of the Thrombosis Service voluntarily chose to start with self-management. During the study, patients could give feedback on the intervention and on the self-management platform; their satisfaction was continuously monitored. Feedback from patients made it possible to optimise their care. All patients will be informed about the results of this study.

\section{Recruitment of patients and non-participation}

Patients of the Saltro Thrombosis Service who received regular care without a self-management programme were eligible for recruitment. In 2013, 8950 patients received usual care from the Saltro Thrombosis Service of which $85 \%$ had a long-term indication. From June 2013 onward, a random selection of 1632 patients was approached for participation in the present study using three methods, (1) information and invitation by letter, (2) personal invitation by specialised nurses and (3) invitation by telephone. Patients who did not wish to start with self-management were invited to participate in a parallel cohort group receiving usual care (group 3), thereby providing valuable information about non-participants. Baseline characteristics of all regular patients of the Saltro
Thrombosis Service also provided valuable information about non-participants.

\section{Intervention}

The intervention in groups 1 and 2 consisted of a training programme in combination with the use of an online self-management portal called Portavita. In group 1, patients used an e-learning that was specifically designed for the PORTALS study (see online multimedia supplementary appendix 1).

Table 2 summarises the programme in all groups: the e-learning modules in group 1, the group training modules in group 2 and the basic training in group 3 . In group 1, the training was provided by e-learning that started with a personal login procedure and an online instruction; the interim control and quality checks were carried out by specialised nurses of the Thrombosis Service. The group course in group two was carried out by specialised and expert healthcare professionals. Both training methods had the same content but were offered in a completely different manner.

In the PORTALS study, the online self-management portal used is called Portavita (see online multimedia supplementary appendix 2). This application combines a patient portal and a healthcare provider portal. The healthcare portal leaves space for the OAT protocol, medication records and information about complications. The Portavita anticoagulation self-management patient portal has become widely accepted; it provides patients with a diary tool for self-monitoring and self-dosage, education; it also allows personal notes and healthcare professionals can send advice and notes to the patient. It implies that the patient analyses a drop of blood using a home INR monitor. The patient can access the web-based patient portal to enter the INR and specific information for the health professional (intervention, bleeding, change in medication, vacation, etc). Clinically validated inbuilt algorithms provide advice regarding the next dose and test interval. The only things needed are an internet connection and a device like a personal computer, tablet or smartphone. When logging on (username + password) for the first time to Portavita, every user was directed to

Table 2 Training methods in group 1, 2 and 3

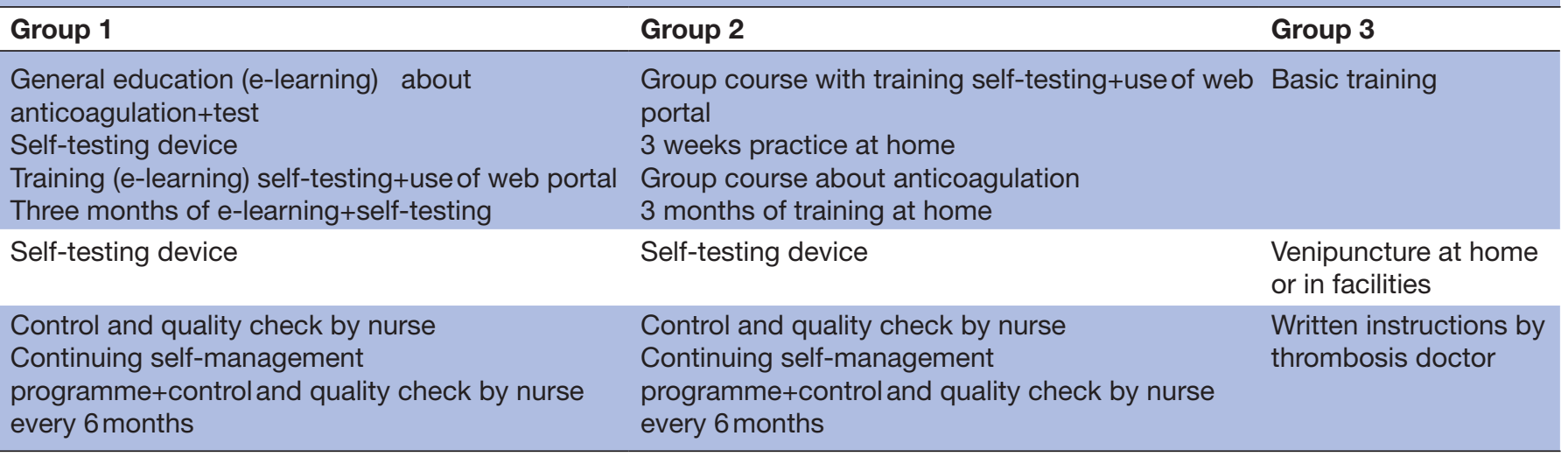


the homepage. From there, users could access all functionalities of the portal. The logon procedure of this portal is based on Dutch security legislation and guidelines (the Dutch Personal Data Protection Act).

\section{Data collection}

INR values, thromboembolic events, bleedings, medication and indication were monitored and registered continuously by patients in the portal and by professionals of the Saltro Thrombosis Service. We measured the INR, complications and medication during a period of 6 months before and 18 months after starting the intervention (ie, 24 months in total). The data collection also consisted of questionnaires (at baseline and after each $3 \times 6$-month period) to measure the determinants and outcomes. Patients of group 1 and 2 received these questionnaires by email, and patients in group 3 by email or by post. In addition, the number of self-tests and use of the portal were continuously registered in the portal. Data on the total population of the Saltro Thrombosis Service were also collected.

\section{Outcome measures and determinants}

The primary outcome of this study was therapeutic control expressed as the INR control over time and severe complications (bleedings and thromboembolic events). To summarise the INR control over time, the percentage of time in therapeutic range (TTR) of INR was used, calculated with the Rosendaal method. ${ }^{30}$ TTR values were calculated for two INR ranges (INR 2-3 and INR 2-3.5) because different calculations are used in Dutch and in international guidelines. TTR was measured at four moments: at 6 months before intervention and at $3 \times 6$-month periods (total of 18 months) after starting the intervention. Serious complications were defined as those needing treatment or medical evaluation. An independent thrombosis specialist was responsible for classifying serious complications at the end of the trial. The total follow-up period for all these measures was 24 months.

Furthermore, the self-management skills of participants were evaluated. Self-management skills were defined as usage of the self-management platform, reflected as the amount of login sessions. Self-monitoring and self-dosage are registered within the same login session. The usage counts were analysed. The determinants were self-efficacy and sociodemographic characteristics. Self-efficacy was measured at baseline using the Generalised Self-Efficacy Scale (GSES), with items scored on a four-point scale with a higher score reflecting higher self-efficacy. ${ }^{31}$ Sociodemographic characteristics were assessed by an online questionnaire addressing the following characteristics: age, gender, education level, marital status, working status (labour) and quality of life (QoL), which was assessed using the EuroQol-5D (EQ-5D) and displayed at baseline. The EQ- $5 \mathrm{D}$ is a five-item questionnaire with a higher score reflecting a higher QoL.

\section{Sample size and statistical methods}

To detect a relevant effect of the new implementation strategy of e-learning or group training $(>5 \%)^{32}$ at a power $80 \%$ and $\alpha=0.05$, we calculated that a sample size of 63 patients was required per group. Considering a $15 \%$ dropout, $72(63 / 0.85)$ patients were needed per study group. Baseline characteristics between the three groups were explored using $\chi^{2}$ tests and Kruskal-Wallis tests.

To investigate the effect of the different implementation methods of training versus the parallel cohort group on TTR, multilevel linear regression modelling (mixed models) was used. First, TTR outcomes were compared between the three groups. A second (mixed models) analysis was used to compare the difference in effect between e-learning and group training (group 1 vs group 2) on TTR. The variable TTR was included as outcome in the model. The periods of TTR measurements (time), the group and the interaction term (timexgroup) were included as predictors.

Both analyses were adjusted for age and gender.

To examine the impact of GSES and education on the effect of the different implementation methods, multiple linear regression analyses were performed with TTR at time point 3 as outcome and GSES and education as predictors. Analyses were adjusted for age and gender.

A linear regression analysis was used to analyse usage (mean number of login sessions) of the portal Portavita in groups 1 and 2.

\section{RESULTS}

A total of 1632 VKA patients of the Saltro Thrombosis Service were invited to participate, of which $56 \%$ $(n=915)$ declined (figure 1). Patients were invited in three different ways: by letter $(n=475)$, by personal invitation during a visit to the Thrombosis Service $(\mathrm{n}=692)$ and by telephone $(\mathrm{n}=465) .717$ patients were interested in participation in the study; 247 patients eventually signed an informed consent. During the process of inviting patients for the PORTALS study, patients were asked about their reasons for not participating: the main reasons were not having a computer or internet, no digital skills, the effort of participating in a trial and their high level of satisfaction with usual care.

Participants were included in the study only after providing written informed consent but, because some patients failed to do this, 247 participants were finally included. Of these, 110 continued to receive regular care (group 3) and 137 patients were randomly divided into group 1 and 2 using a computer program. After randomisation, 63 patients were included in group 1 (e-learning) and 74 in group 2 (group training). Figure 1 summarises the recruitment process, including the reasons for loss to follow-up. 
Invited ( $n=1632)$

Interested $(\mathrm{n}=717)$

Informed consent $(n=247)$

Randomised ( $\mathrm{n}=137)$

Regular care $(\mathrm{n}=110)$

Group 1 e-learning $(n=63)$

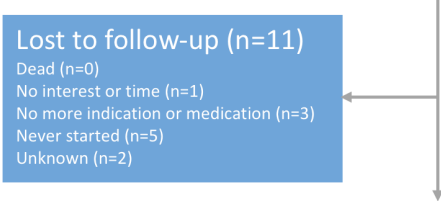

Included in analysis $(n=52)$
Group 2 group training $(n=74)$

Lost to follow-up ( $n=16)$

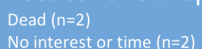

No more indication or medication $(n=2)$
Never started $(n=6)$

Never started $(n=6)$
Unknown $(n=4)$

Included in analysis $(n=58)$
Group 3 usual care $(n=110)$

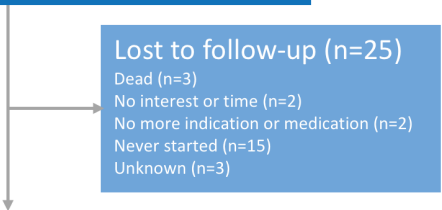

Included in analysis $(n=85)$

Figure 1 Flowchart of the PORTALS study.

\section{Characteristics of the total population of the thrombosis service}

The characteristics of all VKA patients of the Saltro Thrombosis Service in 2015 are shown in table 3 .

\section{Baseline characteristics of study participants}

Table 4 presents the baseline characteristics of the participants: median age was 66.9 years, and median TTR was 54.7 (for INR range 2-3) and 79.1 (for INR range 2-3.5).

\begin{tabular}{lc}
\hline \multicolumn{2}{l}{ Table 3 Clinical characteristics of the population of the } \\
Saltro Thrombosis Service \\
\hline Total patients, N & 11132 \\
Male, N (\%) & $6009(54.0)$ \\
Self-management, N (\%) & $1986(17.8)$ \\
Male self-management, N (\%) & $1260(63.4)$ \\
Medication, N (\%) & \\
Acenocoumarol & $8360(75.1)$ \\
Phenprocoumon & $2761(24.8)$ \\
Warfarin & $10.1)$ \\
Indications, N (\%) & $7430(66.8)$ \\
Atrial fibrillation & $1673(15.0)$ \\
Venous thromboembolism & $720(6.5)$ \\
Artificial valve & $1309(11.8)$ \\
Other & \\
Severe complications, N (\%) & $219(2.0)$ \\
Major bleedings & $8.8)$ \\
Thromboembolism & \\
\hline
\end{tabular}

Of these patients, $66 \%$ had an indication of AF and $77.3 \%$ used acenocoumarol as oral anticoagulation medication. No significant differences were found between the three groups for gender $\left(\chi_{2}^{2}=0.38, \mathrm{p}=0.826\right)$, TTR $\left(\chi_{2}^{2}=3.68\right.$, $\mathrm{p}=0.159)$, indication $\left(\chi_{2}^{2}=8.33, \mathrm{p}=0.215\right)$ and marital status $\left(\chi_{2}^{2}=7.47, \mathrm{p}=0.280\right)$. The three groups differed significantly in age $\left(\chi_{2}^{2}=19.96, \mathrm{p}=0.000\right)$, baseline GSES $\left(\chi_{2}^{2}=15.08, \mathrm{p}=0.001\right)$ and EQ-5D $\left(\chi_{2}^{2}=6.66, \mathrm{p}=0.036\right)$, use of medication $\left(\chi_{2}^{2}=15.23, \mathrm{p}=0.004\right)^{2}$, education level $\left(\chi_{2}^{2}=23.72, \mathrm{p}=0.000\right)$ and work status $\left(\chi_{2}^{2}=13.01, \mathrm{p}=0.043\right)$ (table 4$)$.

\section{Therapeutic control before and after intervention}

Figure 2A shows the TTR values using the INR 2-3 in the three groups, 6 months before the intervention and in the 3x6-month periods after the intervention; the TTR values using the INR 2-3.5 are presented in figure 2B (see online supplementary appendix 3).

Analysis of the three groups showed no significant difference in TTR values over time $\left(\mathrm{F}_{3,631}=0.755, \mathrm{p}=0.520\right)$, between the groups $\left(\mathrm{F}_{2,211}=0.924, \mathrm{p}=0.398\right)$ or between the groups over time $\left(\mathrm{F}_{6,631}=1.009, \mathrm{p}=0.418\right)$.

Analysis of the two self-management groups showed no significant differences in TTR values between the four time periods $\left(\mathrm{F}_{3,378}=0.602, \mathrm{p}=0.614\right)$. Also, no significant differences in TTR were found between group 1 and 2 $\left(\mathrm{F}_{3,378}=0.548, \mathrm{p}=0.460\right)$ or between these two groups over time $\left(\mathrm{F}_{3,378}=1.335, \mathrm{p}=0.263\right)$.

The sensitivity analyses showed that using an INR of 2-3.5, instead of 2-3, had no marked effect on the results, although a significant time effect was found. Results are presented in figure 2B in Appendix 3. 
Table 4 Baseline characteristics of patients with VKA therapy in the PORTALS study

\begin{tabular}{|c|c|c|c|c|c|}
\hline & Group 1 & Group 2 & Group 3 & $\mathrm{p}$ Value & Total \\
\hline $\mathrm{N}$ & 63 & 74 & 110 & & \\
\hline Age in years* (IQR) & $65.0^{\mathrm{a}}(56.2-67.7)$ & $65.8^{\mathrm{a}}(56.4-70.4)$ & $69.6^{\mathrm{b}}(64.0-74.9)$ & $0.00 \dagger$ & $66.9(59.5-72.7)$ \\
\hline TTR INR range 2-3 (\%)* (IQR) & $50.2(39.1-67.1)$ & $52.9(39.0-68.6)$ & $57.4(40.1-75.1)$ & 0.159 & $54.7(39.8-70.7)$ \\
\hline TTR INR range 2-3.5 (\%)* (IQR) & $76.3(67.0-86.0)$ & $77.1(64.1-85.3)$ & $85.6(72.0-93.5)$ & 0.159 & $79.1(68.2-88.8)$ \\
\hline GSES* (IQR) & $3.5^{\mathrm{a}}(3.1-3.8)$ & $3.3^{\mathrm{a}, \mathrm{b}}(3.0-3.7)$ & $3.1^{b}(2.9-3.5)$ & $0.001 \dagger$ & $3.3(3.0-3.7)$ \\
\hline \multicolumn{6}{|l|}{ Indication, N (\%) } \\
\hline $\mathrm{AF}$ & $42(66.7)$ & 44 (59.5) & 77 (70.0) & 0.215 & $163(66)$ \\
\hline Venous thromboembolism & $13(20.6)$ & $18(24.3)$ & $11(10.0)$ & & $42(17)$ \\
\hline Artificial valve & $2(3.2)$ & $3(4.1)$ & $4(3.6)$ & & $9(3.6)$ \\
\hline Other & $6(9.5)$ & $9(12.2)$ & $18(16.4)$ & & $33(13.4)$ \\
\hline Warfarin & $2(3.2)^{a}$ & $0(0)^{\mathrm{a}}$ & $0(0)^{\mathrm{a}}$ & & $2(0.8)$ \\
\hline \multicolumn{6}{|l|}{ Education level, N (\%) } \\
\hline Low & $7(12.1)^{\mathrm{a}}$ & $13(19.1)^{\mathrm{a}}$ & $33(35.9)^{\mathrm{b}}$ & $0.00 \dagger$ & $53(24.3)$ \\
\hline Medium & $24(41.4)^{\mathrm{a}}$ & $32(47.1)^{\mathrm{a}}$ & $46(50.0)^{\mathrm{a}}$ & & $102(46.8)$ \\
\hline High & $27(46.6)^{\mathrm{a}}$ & $23(33.8)^{b}$ & $13(14.1)^{\mathrm{c}}$ & & $63(28.9)$ \\
\hline \multicolumn{6}{|l|}{ Marital status, N (\%) } \\
\hline Married & $49(84.5)$ & $50(73.5)$ & $73(79.3)$ & 0.280 & $172(78.9)$ \\
\hline Widow & $1(1.7)$ & $6(8.8)$ & $4(4.3)$ & & $11(5.0)$ \\
\hline Divorced & $1(1.7)$ & $6(8.8)$ & $4(4.3)$ & & $11(5.0)$ \\
\hline
\end{tabular}

Each superscript $(a, b, c)$ letter denotes a subset of sample categories which do not differ significantly from each other at the 0.05 level.

N Missing questionnaires: GSES 29, EQ5D 32, indication 0, medication 0, education 29, marital status 29, labour 29.

*Values are medians and corresponding IQR.

†Between-group differences $(\mathrm{p}<0.05)$.

AF, atrial fibrillation; EQ-5D, EuroQol five dimensions questionnaire; INR, international normalised ratio; GSES, General Self-efficacy Scale; TTR, time

in therapeutic range; VKA, vitamin $\mathrm{K}$ antagonist.

During the 18-month period after the intervention, across all three groups, a total of three severe complications occurred $(3 / 247=1.2 \%)$ : that is, two muscular bleedings in the e-learning group $(2 / 63=3.2 \%)$ and one cerebrovascular accident among patients receiving group training $(1 / 74=1.4 \%)$; no complications occurred in the usual care group.

\section{Educational level and GSES}

Educational level was not associated with the TTR in the last 6 months $\left(\mathrm{F}_{2198}=2.263, \mathrm{p}=0.107\right)$; education level did not modify the effect of the different implementation methods on TTR $\left(\mathrm{F}_{4,198}=1.659, \mathrm{p}=0.161\right)$.

No association was found between the GSES and TTR in the last 6 months $\left(\mathrm{F}_{1,198}=0.132, \mathrm{p}=0.717\right)$; GSES did not modify the effect of the different implementations methods on TTR $\left(\mathrm{F}_{2,198}=1.762, \mathrm{p}=0.174\right)$.

\section{Usage of the platform}

Figure 3 presents the usage by patients in groups 1 and 2 (using the $\log$ files of the Portavita platform) during the 18 months after start of the intervention. Patients logged on to the platform to register their INR; some also used it to establish their medication dosage or to communicate with healthcare professionals of the Thrombosis Service. There was no significant difference between groups 1 and 2 in usage of the platform during the three time periods $(0-6$ months: mean 20.75, SD 5.20, $\mathrm{F}_{1,109}=0.091, \mathrm{p}=0.764 ; 6-12$ months: mean 13.00, SD 7.0, $\mathrm{F}_{1,109}=0.029, \mathrm{p}=0.866 ; 12-18$ months: mean 12.5, SD 7.39, $\mathrm{F}_{1,109}=1.28, \mathrm{p}=0.260$ ).

\section{DISCUSSION}

In the present study, no differences were found in therapeutic control and usage of the platform between anticoagulation 


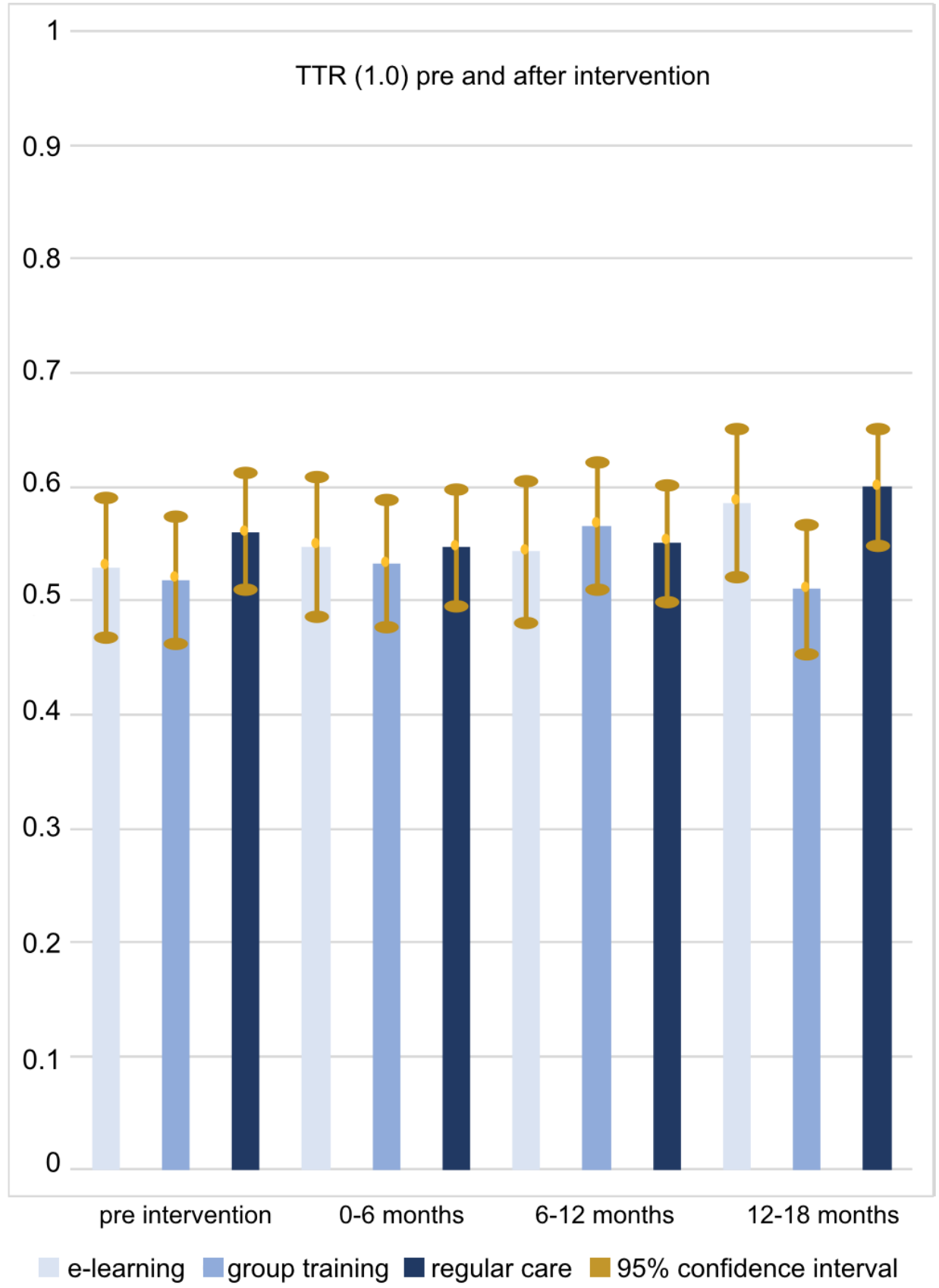

Figure 2 A Health status based on TTR (for INR range 2-3) for the three groups. INR, international normalised ratio; TTR, time in therapeutic.

self-management patients trained by e-learning and by group training. Moreover, the clinical results for self-management patients were similar to those of patients receiving regular care. Therefore, we conclude that, with adequate training through e-learning or group training, self-management is safe and reliable for a selected proportion of motivated patients receiving VKA. The PORTALS study provides valuable information on different implementation methods of OAT self-management, including eHealth.

\section{Strengths and limitations}

This PORTALS study has several strengths. First, the study investigates the effect of different education programmes in a situation as close to 'real life' as possible, integrated in a self-management programme including eHealth, on clinical outcomes and self-management skills. The study also adds evidence to the existing body of knowledge on implementation of eHealth; this is important because local political/financial factors have a major impact on successful integration of eHealth in daily practice and 


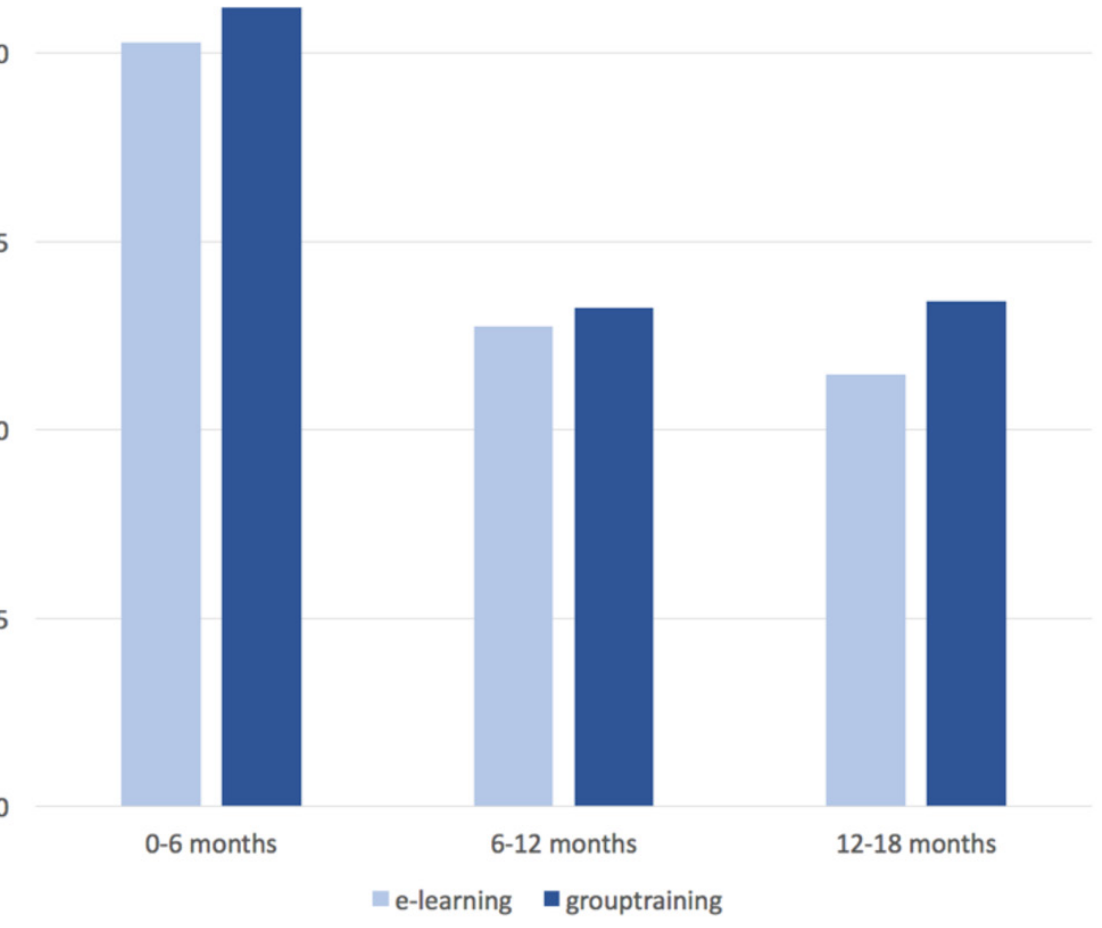

Figure 3 Usage of the platform in group 1 and group 2 after start of the intervention.

because self-management is important for patients who will use VKAs in the future. ${ }^{33}$

This study also has limitations. First, a randomised controlled trial (RCT) was not feasible in our setting of an implementation design in a real-life healthcare system with patients who have differing demands. Instead, an observational study was considered the best option for our context, that is, patients cannot be denied or forced to start with self-management. Furthermore, self-management skills imply behavioural changes. However, behavioural changes require time, whereas the study period was restricted to 18 months. This study also has limitations typically associated with eHealth trials. For example, as patients were free to volunteer, bias might have occurred in our study groups. Users were self-selected and were, presumably, motivated to use the education programme (including the web-based platform) as would be expected in a real-life setting. Of the 1632 invited OAT patients, 247 patients $(15 \%)$ were willing to participate and provided informed consent. However, only 137 patients (8.4\% of invited patients) wanted to participate in the self-management groups and were randomised; other studies have a similar low recruitment rate for self-management trials. ${ }^{34}$ This phenomenon might have affected the measurability of differences and might also reduce differences between the groups. The high number of participants lost to follow-up in our study ('law of attrition'; the phenomenon of participants stopping usage) is a common finding in eHealth evaluations and one of the fundamental and methodological challenges in the evaluation of eHealth apps. ${ }^{35}$ The loss to follow-up is high with a risk of biased results due to user bias; therefore, these results are only applicable for users of eHealth.

The total population of the Thrombosis Service showed a lower percentage of men than the participants of the present study, although the distribution of indications/ medication was similar. In the total population, the percentage of severe complications was low (bleedings $2 \%$, thromboembolism $0.8 \%$ ); during our study period the percentage of complications was also low (group e-learning $=3.2 \%$; group training $=1.4 \%$; group usual care $=0 \%$ ), indicating a high quality of thrombosis care.

During the process of inviting patients for the PORTALS study, we asked their reasons for not participating (main reasons were: not having a computer/internet, no digital skills, the effort of participating and their high level of satisfaction with usual care). The group with usual care differed significantly from the self-management groups on several baseline characteristics: that is, patients in usual care were older, had a lower education level and fewer of them had paid work. Also, they had a lower GSES and EQ-5D and made less use of acenocoumarol. Patients in the total population of the Thrombosis Service and in the usual care group, might have different wishes and expectations towards care than patients that chose for a 
self-management programme; that is, self-management programmes are suitable for patients that are highly motivated and have skills for self-management tasks.

Finally, to measure a significant difference in therapeutic control, 72 patients were needed in each group. Although these numbers were not entirely met in group 1 (e-learning), analysis of the groups should be sufficiently powered to detect relevant differences. In addition, the high number of INR data points collected before and after the intervention has a substantial impact on the strength of the design and the multilevel linear analysis.

Due to these limitations, caution is required when generalising our results to general practice. However, the practical applicability of our results for other specialised OAT centres is positive, that is, the study provides practical insight into successful implementation of self-management programme consisting of high-quality training and usage of a patient platform.

\section{Interpretation of findings}

No overall significant differences in therapeutic control were found between the three groups; also, there was no difference in therapeutic control between the group with e-learning and group training. Therapeutic INR control was good in all groups; in the last 6 months of the intervention period, all groups spent around $58 \%$ of time within the narrow therapeutic range $2-3$ and $83 \%$ of time within the therapeutic range 2-3.5; this indicates high quality and is comparable to other studies. ${ }^{34}{ }^{36}$ Anticoagulation control levels around $60 \%$ for TTR of INR range 2-3 are considered safe. ${ }^{36-38}$ In studies conducted outside specialised care facilities in several different regions, TTR ranged from $40 \%$ to $70 \%$. $^{13}$ The national guidelines for the INR range changed during the last 6 months of our PORTALS study; this had a negative impact on the TTR during our last measurement period. Complication rates also compared favourably with international data; our overall adverse event rate was low compared to other studies. ${ }^{39-41}$

In comparison to literature, the baseline quality of OAT management in the present study can be considered high in all groups; therefore, further improvement through a self-management programme including education was difficult to achieve and the outcomes in the groups remained the same. Finally, both training methods were comparable on the effect of anticoagulation control; for patients and healthcare professionals this means that a good e-learning programme is a good alternative for labour-intensive group trainings. Based on our study, we recommend considering self-management programmes supported by e-learning as the preferred plan of action for self-management for anticoagulation patients. Furthermore, self-management with an e-learning component is suitable for motivated patients with sufficient digital skills; in our opinion, regular anticoagulation care needs to remain available for the rest of the population.

Self-efficacy and educational level of users had no impact on therapeutic control for the different implementation methods. The construct of perceived self-efficacy reflects an optimistic self-belief ${ }^{31}$; a correlation can be understood based on the belief that one can perform a novel or difficult task or cope with adversity (indicating a higher self-efficacy). In the present study, self-efficacy was comparable to that in a healthy Dutch population. ${ }^{42} 43$

The practical value of the Portavita portal is very high for patients because of the functionalities of self-monitoring, self-dosage and digital advice from professional healthcare providers. Because patients use the self-management programme, regular visits to medical facilities are unnecessary. Patients can manage their anticoagulation in their own time and in their own chosen place. Thus, using the self-management programme gives them (extra) freedom; this might be a strong motivating factor for using the programme. Also, the training programmes were sound and sustainable during the entire study period, probably stimulating patients to persevere with their self-management programme. Moreover, e-learning and group training led to the same usage and, therefore, the same self-management skills. Therefore, we conclude that our e-learning and group training provide a good start for OAT patients that voluntarily start with a self-management programme including eHealth.

Self-management programmes with eHealth technologies for chronic conditions can be used to enhance self-management and revise the Chronic Care Model; patients who actively participate in their care achieve valuable and sustained improvement in well-being. ${ }^{44}{ }^{45} \mathrm{In}$ many eHealth studies, use of a Personal Health Record or self-management platform can promote an informed/ activated patient and augment the Chronic Care Model for self-management support and productive interactions; even though a direct dosage-effect relation (usually analysed in a classical RCT) is not common in eHealth. ${ }^{46}$ Self-management programmes with good training and practical eHealth platforms have the potential to make chronic care personalised in a blended care model; every patient needs a different approach for optimal therapeutic control. Healthcare providers need to embrace a different role and release tight protocols. ${ }^{47}$ Individual patients have different expectations and wishes, which should be a topic of conversation with each patient. The general scientific basis for self-management applies perfectly to anticoagulation patients, which is confirmed in our study.

More studies are needed (preferably with larger sample groups, and including non-users) to gain more insight into the preferences of various patient groups, as well as the related costs.

The substantial workload generated by integrating a web-based platform in an OAT self-management programme emphasises the importance of piloting and assessing workforce implications for OAT management centres. The present results provide additional insight into the organisational aspects of the implementation of education programmes into a self-management programme with a platform, including the need 
to educate and coach patients in the use of web-based platforms.

\section{CONCLUSION}

Our main finding is that there were no differences in therapeutic control and usage of a supporting eHealth platform between anticoagulation self-management patients trained by e-learning and by group training. Moreover, we found that clinical results for self-management patients are comparable to those of patients receiving usual care. We conclude that with appropriate and sound training through e-learning or group training, self-management seems safe and reliable for a selected proportion of motivated patients receiving oral anticoagulation treatment. The PORTALS study provides valuable information on different implementation methods of oral anticoagulation self-management, including eHealth.

\section{ACKNOWLEDGEMENTS}

The authors wish to thank all patients and caregivers within the Saltro Thrombosis Service Centre. The authors thank Pim Assendelft for his valuable contribution to the design and Joke van der Feest, Nynke Wiersma, Carola Guse and Sandra Claassen for their research assistance. The authors also thank Nan van Geloven for reviewing the statistical analysis.

Contributors ET is the principle investigator and contributed to all aspects of the research. NV assisted on all aspects. MK assisted on the statistical analysis. NV, MK, LH, IT, MN and NC are responsible for revising the manuscript several times. IT is responsible for the acquisition of data. NC is responsible for the concept and design. All authors read and approved the final manuscript.

Funding This work did not receive any funding.

Competing interests None declared.

Ethics approval The Medical Ethics Committee of the LUMC approved this study (Reference No. P12.278).

Provenance and peer review Not commissioned; externally peer reviewed.

Data sharing statement Data will be made available for sharing where available and appropriate.

Open Access This is an Open Access article distributed in accordance with the Creative Commons Attribution Non Commercial (CC BY-NC 4.0) license, which permits others to distribute, remix, adapt, build upon this work non-commercially, and license their derivative works on different terms, provided the original work is properly cited and the use is non-commercial. See: http://creativecommons.org/ licenses/by-nc/4.0/

(c) Article author(s) (or their employer(s) unless otherwise stated in the text of the article) 2017. All rights reserved. No commercial use is permitted unless otherwise expressly granted.

\section{REFERENCES}

1. Streiff MB, Carolan HT, Hobson DB, et al. Lessons from the Johns Hopkins Multi-Disciplinary Venous Thromboembolism (VTE) Prevention Collaborative. BMJ 2012;344:e3935.

2. $\mathrm{CBO}$ Richtlijn Diagnostiek. preventie en behandeling van Veneuze trombo-embolie en Secundaire Preventie Arteriele trombose 2009. [CBO Diagnostics Guidelines, prevention and treatment of venous thromboembolism and secondary prevention of arterial thrombosis 2009.
3. Schnabel RB, Yin X, Gona P, et al. 50 year trends in atrial fibrillation prevalence, incidence, risk factors, and mortality in the Framingham Heart Study: a cohort study. Lancet 2015;386:154-62.

4. You JJ, Singer DE, Howard PA, et al. 9th edition. American College of Chest Physicians Evidence-Based Clinical Practice Guidelines. Antithrombotic Therapy for Atrial Fibrillation: Antithrombotic Therapy and Prevention of Thrombosis. Chest 2012;141:e531S-75.

5. Pinede L, Ninet J, Duhaut P, et al. Comparison of 3 and 6 months of oral anticoagulant therapy after a first episode of proximal deep vein thrombosis or pulmonary embolism and comparison of 6 and 12 weeks of therapy after isolated calf deep vein thrombosis. Circulation 2001;103:2453-60.

6. Torn M, Bollen WL, van der Meer FJ, et al. Risks of oral anticoagulant therapy with increasing age. Arch Intern Med 2005;165:1527-32.

7. Heneghan C, Ward A, Perera R, et al. Self-monitoring of oral anticoagulation: systematic review and meta-analysis of individual patient data. The Lancet 2012;379:322-34.

8. Hylek EM, Go AS, Chang Y, et al. Effect of intensity of oral anticoagulation on stroke severity and mortality in atrial fibrillation. N Engl J Med 2003;349:1019-26.

9. Chai-Adisaksopha C, Crowther M, Isayama T, et al. The impact of bleeding complications in patients receiving target-specific oral anticoagulants: a systematic review and meta-analysis. Blood 2014;124:2450-8.

10. Cannegieter SC, Rosendaal FR, Wintzen AR, et al. Optimal oral anticoagulant therapy in patients with mechanical heart valves. $N$ Engl J Med Overseas Ed 1995;333:11-17.

11. Kearon C, Ginsberg JS, Kovacs MJ, et al. Comparison of lowintensity warfarin therapy with conventional-intensity warfarin therapy for long-term prevention of recurrent venous thromboembolism. N Engl J Med 2003;349:7.

12. Kimmel SE, Chen Z, Price M, et al. The influence of patient adherence on anticoagulation control with warfarin: results from the International Normalized Ratio Adherence and Genetics (IN-RANGE) Study. Arch Intern Med 2007;167:229-35.

13. Singer DE, Hellkamp AS, Piccini JP, et al. Impact of global geographic region on time in therapeutic range on warfarin anticoagulant therapy: data from the ROCKET AF clinical trial. J Am Heart Assoc 2013;2:e000067.

14. McLean S, Protti D, Sheikh A. Telehealthcare for long term conditions. BMJ 2011;342:d120.

15. Gadisseur AP, Kaptein AA, Breukink-Engbers WG, et al. Patient self-management of oral anticoagulant care vs. management by specialized anticoagulation clinics: positive effects on quality of life. $J$ Thromb Haemost 2004;2:584-91.

16. McCahon D, Murray ET, Murray K, et al. Does self-management of oral anticoagulation therapy improve quality of life and anxiety? Fam Pract 2011;28:134-40.

17. Heneghan CJ, Garcia-Alamino JM, Spencer EA, et al. Self-monitoring and self-management of oral anticoagulation. Cochrane Heart Group 2016.

18. Newman S, Steed L, Mulligan K. Self-management interventions for chronic illness. Lancet 2004;364:1523-37.

19. Bouillon K, Bertrand M, Maura G, et al. Risk of bleeding and arterial thromboembolism in patients with non-valvular atrial fibrillation either maintained on a vitamin $\mathrm{K}$ antagonist or switched to a non-vitamin K-antagonist oral anticoagulant: a retrospective, matched-cohort study. Lancet Haematol 2015;2:e150-e159.

20. Ageno W, Mantovani LG, Haas S, et al. Safety and effectiveness of oral rivaroxaban versus standard anticoagulation for the treatment of symptomatic deep-vein thrombosis (XALIA): an international, prospective, non-interventional study. Lancet Haematol 2016;3:e12-e21.

21. Lin L, Lim WS, Zhou HJ, et al. Clinical and safety outcomes of oral antithrombotics for stroke prevention in atrial fibrillation: a systematic review and network meta-analysis. J Am Med Dir Assoc 2015;16:1103.e1-9.

22. Lorig KR, Ritter P, Stewart AL, et al. Chronic disease selfmanagement program: 2-year health status and health care utilization outcomes. Med Care 2001;39:1217-23.

23. Mishali M, Omer H, Heymann AD. The importance of measuring selfefficacy in patients with diabetes. Fam Pract 2011;28:82-7.

24. Simpson E, Jones MC. An exploration of self-efficacy and selfmanagement in COPD patients. Br J Nurs 2013;22:1105-9.

25. Rajati F, Sadeghi M, Feizi A, et al. Self-efficacy strategies to improve exercise in patients with heart failure: A systematic review. ARYA Atheroscler 2014;10:319-33.

26. Kontos E, Blake KD, Chou WY, et al. Predictors of eHealth usage: insights on the digital divide from the Health Information National Trends Survey 2012. J Med Internet Res 2014;16:e172. 
27. Barlow J, Wright C, Sheasby J, et al. Self-management approaches for people with chronic conditions: a review. Patient Educ Couns 2002;48:177-87.

28. van Bokhoven MA, Kok G, van der Weijden $T$. Designing a quality improvement intervention: a systematic approach. Qual Saf Health Care 2003;12:215-20.

29. Talboom-Kamp EP, Verdijk NA, Talboom IJ, et al. PORTALS: design of an innovative approach to anticoagulation management through eHealth. BMC Health Serv Res 2017;17:213.

30. Rosendaal FR, Cannegieter SC, van der Meer FJ, et al. A method to determine the optimal intensity of oral anticoagulant therapy. Thromb Haemost 1993;69:236-9.

31. Scholz U, Gutiérrez-Doña B, Sud S, et al. Is general self-efficacy a universal construct? Psychometric findings from 25 countries. Eur J Psychol Assess 2002;18:242-51.

32. Heneghan C, Ward A, Perera R, et al. Self-monitoring of oral anticoagulation: systematic review and meta-analysis of individual patient data. Lancet 2012;379:322-34.

33. Nijland N. Thesis: Grounding eHealth. Towards an holistic framework for sustainable eHealth technologies. University of Twente 2011. ISBN: 9789036531337.

34. Gadisseur AP, Breukink-Engbers WG, van der Meer FJ, et al. Comparison of the quality of oral anticoagulant therapy through patient self-management and management by specialized anticoagulation clinics in the Netherlands: a randomized clinical trial. Arch Intern Med 2003;163:2639-46.

35. Eysenbach G. The law of attrition. J Med Internet Res 2005;7:e11.

36. Menéndez-Jándula B, Souto JC, Oliver A, et al. Comparing selfmanagement of oral anticoagulant therapy with clinic management: a randomized trial. Ann Intern Med 2005;142:1-10.
37. Fitzmaurice DA, Murray ET, McCahon D, et al. Self management of oral anticoagulation: randomised trial. BMJ 2005;331:1057.

38. Ryan F, Byrne S, O'Shea S. Randomized controlled trial of supervised patient self-testing of warfarin therapy using an internetbased expert system. J Thromb Haemost 2009;7:1284-90.

39. van Rein N, Lijfering WM, Bos MH, et al. Objectives and design of BLEEDS: a Cohort study to identify new risk factors and predictors for major bleeding during treatment with Vitamin $\mathrm{K}$ Antagonists. PLoS One 2016;11:e0164485.

40. Gage BF, Yan Y, Milligan PE, et al. Clinical classification schemes for predicting hemorrhage: results from the National Registry of Atrial Fibrillation (NRAF). Am Heart J 2006;151:713-9.

41. Chai-Adisaksopha C, Crowther M, Isayama T, et al. The impact of bleeding complications in patients receiving target-specific oral anticoagulants: a systematic review and meta-analysis. Blood 2014;124:2450-8.

42. Schwarzer R. Self-efficacy: thought control of action. Hemisphere Publishing Corporation 1992. ISBN: 9781560322696.

43. Luszczynska A, Gutiérrez-Doña B, Schwarzer R. General selfefficacy in various domains of human functioning: Evidence from five countries. Int J Psychol 2005;40:80-9.

44. Siminerio LM. The role of technology and the chronic care model. $J$ Diabetes Sci Technol 2010;4:470-5.

45. Stellefson M, Chaney B, Barry AE, et al. Web 2.0 chronic disease self-management for older adults: a systematic review. J Med Internet Res 2013;15:e35.

46. Archer N, Fevrier-Thomas U, Lokker C, et al. Personal health records: a scoping review. J Am Med Inform Assoc 2011;18:515-22.

47. Sun X, Guyatt GH. Interventions to enhance self management support. BMJ 2013;346:f3949 